\title{
A ARBITRAGEM ENVOLVENDO A ADMINISTRAÇÃO PÚBLICA
}

\author{
CARMEN TIBURCIO*
}

\begin{abstract}
Resumo:
A utilização da via arbitral como método alternativo de solução de conflitos já se consagrou como praxe no âmbito do comércio internacional. Entretanto, com a crescente participação da iniciativa privada na realização em diferentes projetos do Estado, cumpre investigar a questão das arbitragens envolvendo entes da Administração Pública direta e indireta conforme decidido pelos tribunais brasileiros.
\end{abstract}

Palavras-chave: arbitragem - administração pública - sociedade de economia mista compromisso arbitral.

\begin{abstract}
:
Arbitration is an alternative dispute resolution method which has become praxis within International Trade Law. In Brazil, despite increasing participation of private agents in the realization of government projects, such proceedings still represent an uncertainty when members of Direct and Indirect Public Administration are supposed to take part on them.
\end{abstract}

Keywords: arbitration - Public administration - State-controlled private companies - arbitration clause.

\section{Recurso Especial $n^{\circ}$ 606.345/Rio Grande do Sul} $2^{\mathrm{a}}$ Turma, Rel. Min. João Otávio de Noronha, unânime, j. 17.05.07, DJ 08.06.07.

Decisão: PROCESSO CIVIL. JUÍZO ARBITRAL. CLÁUSULA COMPROMISSÓRIA. EXTINÇÃO DO PROCESSO. ART. 267, VII, DO CPC. SOCIEDADE DE ECONOMIA MISTA. DIREITOS DISPONÍVEIS. 1. Cláusula compromissória é o ato por meio do qual as partes contratantes formalizam seu desejo de submeter à arbitragem eventuais divergências ou litígios passíveis de ocorrer ao longo da execução da avença. Efetuado o ajuste, que só pode ocorrer em hipóteses envolvendo direitos disponíveis, ficam os contratantes vinculados à solução extrajudicial da pendência. 2. A eleição da cláusula compromissória é causa de extinção do processo sem julgamento do mérito, nos termos do art. 267, inciso VII, do Código de Processo Civil. 3. São válidos e eficazes os contratos firmados pelas sociedades de economia mista exploradoras de atividade econômica de produção ou comercialização de bens ou de prestação de serviços $\left(\mathrm{CF}\right.$, art. $\left.173, \S 1^{\circ}\right)$ que estipulem cláusula compromissória submetendo à arbitragem eventuais litígios decorrentes do ajuste. 4. Recurso especial provido.

A possibilidade de a Administração Pública (direta e indireta) participar de arbitragens é bastante controvertida no direito brasileiro. O tema é tão polêmico que a PEC n ${ }^{\circ} 29$ - que se transformou na EC no 45/2004 - visava incluir no art. 98 da Constituição Federal o

\footnotetext{
* Professora Adjunta de Direito Internacional Privado e de Direito Processual Internacional da Faculdade de Direito da UERJ. Mestre e Doutora em Direito Internacional pela Faculdade de Direito da Universidade de Virginia, EUA. A autora agradece a Marisa Choeypant a colaboração na pesquisa.
} 
seguinte texto que impediria a utilização da arbitragem nos contratos celebrados pela Administração Pública:

“Art. 11. O art. 98 passa a vigorar com a seguinte redação:

'Art. 98. .....

$\$ 1^{\circ}$ Ressalvadas as entidades de direito público, os interessados em resolver seus conflitos de interesse poderão valer-se de juízo arbitral, na forma da lei"”.

Felizmente, o dispositivo não constou na versão aprovada da Emenda Constitucional da Reforma do Judiciário. Todavia, constata-se ainda uma enorme insegurança a respeito, visto que a questão não tem recebido tratamento uniforme da doutrina e da jurisprudência.

A dificuldade na aceitação da arbitragem em tais casos decorre principalmente de duas razões principais: (1) o princípio da legalidade previsto em sede constitucional e (2) a legislação brasileira que trata dos contratos celebrados pela administração pública.

O princípio da legalidade estabelecido em sede constitucional (CF, art. 37), como tradicionalmente definido, determina que os agentes públicos só podem agir por imposição ou autorização legal. Assim, na ausência de lei autorizadora, extrai-se desse princípio uma vedação à arbitragem nos contratos administrativos.

Por outro lado, é da tradição da legislação brasileira a exigência, nos contratos administrativos, de cláusula que eleja o foro da sede da Administração. O Decreto $\mathrm{n}^{\circ}$ 15.783/22 (que regulamentou o Código de Contabilidade da União - Decreto Legislativo $\mathrm{n}^{\circ}$ 4.536/22) assim dispunha (art. 775, § $1^{\circ}$ ):

"A estipulação dos contratos administrativos compreende cláusulas essenciais e cláusulas acessórias. São cláusulas essenciais, e como tais não podem ser omitidas em contrato algum, sob pena de nulidade: (...) e) nos contratos com pessoas naturais ou jurídicas domiciliadas no estrangeiro, a cláusula que declara competente o foro nacional brasileiro, para dirimir quaisquer questões originadas dos mesmos contratos".

O Decreto-lei n ${ }^{\circ}$ 2.300/86 (antigo estatuto jurídico das licitações e contratos administrativos de obras, serviços, compras, alienações, concessões e locações no âmbito da Administração Federal) estabelecia (art. 45, p. único):

"Nos contratos celebrados com pessoas físicas e jurídicas domiciliadas no estrangeiro deverá constar, necessariamente, cláusula que declare competente o foro do Distrito Federal para dirimir qualquer questão contratual, vedada a instituição de juízo arbitral". 
Menos de um ano após a sua vigência, foi promulgado o Decreto-lei $\mathrm{n}^{\circ}$ 2.348/87, que alterou alguns dispositivos do Decreto-lei $\mathrm{n}^{\circ} 2.300$, entre eles o art. 45, que passou a ter a seguinte redação:

"Nos contratos celebrados pela União Federal ou suas autarquias, com pessoas físicas ou jurídicas domiciliadas no estrangeiro, deverá constar, necessariamente, cláusula que declare competente o foro do Distrito Federal para dirimir qualquer questão contratual, salvo o disposto no $\$ 13$ do artigo 25, permitido nesse caso o juízo arbitral".

A atual Lei $\mathrm{n}^{\mathrm{o}}$ 8.666/93, sobre licitações e contratos administrativos, reproduz essa mesma regra no art. $55, \S 2^{\circ}$ :

"Nos contratos celebrados pela Administração Pública com pessoas físicas ou jurídicas, inclusive aquelas domiciliadas no estrangeiro, deverá constar necessariamente cláusula que declare competente o foro da sede da Administração para dirimir qualquer questão contratual, salvo o disposto no $6^{\circ}$ do art. 32 desta Lei".

Portanto, esse diploma em vigor restringe a solução de qualquer litígio ao foro da sede da Administração, pelo que se pode concluir serem inválidas, em tais contratos, as cláusulas de eleição de foro estrangeiro. Note-se que o dispositivo em questão traduz um comando positivo (exigindo claramente a eleição do foro da sede da Administração), e não negativo (proibindo a eleição de foro estrangeiro). Assim, com base nessa Lei é possível chegarse a uma conclusão e a um questionamento: nos contratos administrativos, como regra geral, não se admite eleição de foro estrangeiro e a aceitação da cláusula compromissória é duvidosa.

$\mathrm{O} \S 6^{\circ}$ do art. 32 abre exceções a essa regra geral, nas hipóteses de: a) licitação internacional para a aquisição de bens e serviços, cujo pagamento foi feito com o produto de financiamento concedido por organismo financeiro internacional de que o Brasil faça parte, ou por agência estrangeira de cooperação; b) contratação de empresa estrangeira para a compra de equipamentos fabricados e entregues no exterior; c) aquisição de bens e serviços realizada por unidades administrativas com sede no exterior. Como exceções à regra geral, tais hipóteses são taxativas e devem ser interpretadas restritivamente.

Há algumas leis específicas que admitem a participação da Administração Pública em arbitragens: Lei $n^{\circ}$ 5.662/71, art. 5 (BNDES); Decreto-lei $\mathrm{n}^{\circ}$ 1.312/74, art. 11 (empréstimos); Lei $n^{\circ} 8.693 / 93$, art. $1^{\circ} \S 8^{\circ}$ (transporte ferroviário); Lei $n^{\circ} 8.987 / 95$, art. 23 (concessões); Lei $n^{\circ}$ 9.472/97, art. 93, XV (telecomunicações); Lei $\mathrm{n}^{\circ}$ 9.478/97, art. 43, X (petróleo); Lei no 10.848/04, art. $4^{\text {o }} \S 6^{\circ}$ (CCEE); Lei no 11.079/04, art. 11 (PPP). 
Pode-se questionar se o quadro acima descrito foi alterado pela Carta da República, à luz das inovações trazidas pela Emenda Constitucional nº 19, de 1998. O art. 173, § $1^{\circ}$, do Texto Maior, trata de empresa pública, sociedade de economia mista e suas subsidiárias que exploram atividade econômica; o art. 175 cuida das empresas que prestam serviços públicos, diretamente ou por meio de concessão ou permissão. $O$ art. $173, \S 1^{\circ}$, determina:

“A Lei estabelecerá o estatuto jurídico da empresa pública, da sociedade de economia mista e de suas subsidiárias que explorem atividade econômica de produção ou comercialização de bens ou de prestação de serviços, dispondo sobre: (...) III - licitação e contratação de obras, serviços, compras e alienações, observados os princípios da administração pública".

Há duas correntes principais relativas a esse dispositivo: (1) tal norma não é auto-aplicável, dependendo de lei que estabeleça o estatuto jurídico das empresas estatais que exerçam atividade econômica; como tal lei ainda não foi promulgada, aplica-se a Lei ${ }^{\circ}$ 8.666; (2) a regra é dotada de eficácia contida, ou seja, desde já fica afastada a Lei $n^{0} 8.666$ e são aplicados os princípios gerais da Administração Pública, podendo uma lei futura vir a disciplinar tal regime jurídico.

Parte da doutrina entende que a arbitragem não pode ser estabelecida pela Administração Pública sem fundamento legal, por imposição do princípio da legalidade. Há alguns autores, porém, que defendem a possibilidade de clausular-se arbitragem nos contratos administrativos em geral (de forma mais ou menos ampla). Na verdade, há três posições sobre a matéria, que podem ser sistematizadas da seguinte forma ${ }^{1}$ :

(a) Uma corrente sustenta que a arbitragem seria legítima em qualquer contrato administrativo com fundamento no art. 54, caput, da Lei $n^{\circ}$ 8.666/93, que dispõe serem aplicáveis supletivamente aos contratos administrativos, os princípios da teoria geral dos contratos, in verbis: "Os contratos administrativos de que trata esta lei regulam-se pelas suas cláusulas e pelos preceitos de direito público, aplicando-lhes, supletivamente, os princípios da teoria geral dos contratos e as disposições de direito privado".2.

\footnotetext{
${ }^{1}$ Como sistematizado por Luís Roberto Barroso, Sociedade de Economia Mista Prestadora de Serviço Público, Cláusula Arbitral Inserida em Contrato Administrativo sem Prévia Autorização Legal. Invalidade. In: Temas de Direito Constitucional, t. II, 2003, p. 620.

${ }^{2}$ Essa é a opinião de Adilson Abreu Dallari, Arbitragem na Concessão de Serviço Público, Revista de Informação Legislativa do Senado Federal 128:65, 1995, como se vê do seguinte trecho: "Apreciando o processo de contratação de concessionário para exploração da ponte Rio-Niterói, o Tribunal de Contas da União (Decisão $\left.n^{\circ} 763 / 94\right)$ determinou o seguinte: c) excluir as disposições dos itens 204 e 208 do Edital de Propostas de Tarifa que
} 
(b) Outra corrente extrai de leis que autorizam a Administração a submeterse à arbitragem em determinadas situações - como a Lei de concessões de serviços públicos, já referida (Lei n 8.987/95, art. 23, XV) - uma autorização generalizada para que a arbitragem seja adotada em qualquer circunstância ${ }^{3}$.

(c) Por fim, há ainda o argumento de que a arbitragem estaria autorizada genericamente para as sociedades de economia mista e empresas públicas exploradoras de atividade econômica por força do art. $173, \S 1^{\circ}$, da Constituição de 1988 , no qual se prevê que elas estão sujeitas ao regime jurídico de direito privado ${ }^{4}$.

Por outro lado, a jurisprudência nacional parece estar flexibilizando a matéria, e já há casos em que se admitiu a participação da Administração em arbitragens, sem qualquer lei autorizativa.

$\mathrm{Na}$ esfera administrativa, porém, o TCU tem se mantido firme no entendimento de que não é possível a participação da Administração em arbitragens sem lei autorizativa (decisão $286 / 93^{5}$, decisão $763 / 94^{6}$, decisão $188 / 95^{7}$, decisão $394 / 95^{8}$, acórdão

estabelecem a arbitragem como método para a resolução de conflitos entre a concessionária e o DNER, ante a inexistência de fundamento legal para adoção de tal instituto em contratos administrativos, consoante decisão do Tribunal de 15.7.93 (Ata $n^{\circ}$ 29/93. Decisão 287/93 - Plenário).

Tal entendimento, quando estabelecido, já estava equivocado, pois efetivamente já havia naquela ocasião fundamento legal para a arbitragem, embora não explícito.

Com efeito, o art. 54 da Lei $n^{\circ}$ 8.666, de 21.6.93, assim dispõe: (...).

Isso significa que poder-se-ia ter aplicado, supletivamente e no que coubesse, o disposto nos artigos 1.037 a 1.048 do Código Civil (que trata do Compromisso, ao dispor sobre o Direito das Obrigações), e nos artigos 1.072 a 1.102 do Código de Processo Civil (que cuida Do Juízo Arbitral)".

${ }^{3}$ É o que resulta de uma leitura ampliativa de passagem escrita por Caio Tácito, Arbitragem nos Litígios Administrativos, Revista de Direito Administrativo 210:112, 1997: “A questão do cabimento do juízo arbitral, em matéria pertinente a contratos administrativo, assumiu aspecto novo com o advento da Lei $n$. 8.987/95, que dispõe sobre concessões e permissões de serviços e obras públicas.

(...)

A partir do expresso critério quanto aos contratos de concessão, cujo modelo federal se transmite como norma geral aos planos estadual e municipal, a doutrina passou a reconhecer o ingresso do arbitramento em matéria administrativa".

${ }^{4} \mathrm{CF} / 88$, art. $73, \S 1^{\circ}$ : “A empresa pública, a sociedade de economia mista e outras entidades que explorem atividade econômica sujeitam-se ao regime jurídico próprio das empresas privadas, inclusive quanto às obrigações trabalhistas e tributárias."

A EC $n^{\circ}$ 19/98 deu a seguinte redação ao dispositivo: "A lei estabelecerá o estatuto jurídico da empresa pública, da sociedade de economia mista e de suas subsidiárias que explorem atividade econômica de produção ou comercialização de bens ou de prestação de serviços, dispondo sobre:

(...)

II - a sujeição ao regime jurídico próprio das empresas privadas, inclusive quanto aos direitos e obrigações civis, comerciais, trabalhistas e tributárias".

${ }^{5}$ TCU, DOU 4 ago. 1993, Decisão 286/93, Plenário, Rel. Min. Homero Santos. Interessado: Dep. Fed. Paulino Cícero, Min. de Estado de Minas e Energia. Entidade: Companhia Hidro-Elétrica do São Francisco.

${ }^{6}$ TCU, DOU 3 jan. 1995, Decisão 763/94, Plenário, Rel. Min. Carlos Átila Álvares da Silva. Responsável: Fabiano Vivacqua - Diretor-Geral do DNER. Entidade: Departamento Nacional de Estradas de Rodagem - DNER. 
$584 / 03^{9}$, decisão $215 / 04^{10}$, acórdão $587 / 03^{11}$, acórdão $631 / 03^{12}$, acórdão $1271 / 05^{13}$, acórdão $537 / 06^{14}$ e acórdão 1099/06 ${ }^{15}$ ).

Na jurisprudência, a matéria é bastante polêmica, encontrando-se decisões que admitem a arbitragem, aparentemente sem lei autorizativa, e decisões que entendem ser a lei específica imprescindível.

No STF, admitiu-se a arbitragem no Caso Minas x Werneck, mesmo sem lei autorizativa, mas o caso foi anterior a $1922^{16}$, quando o Decreto $\mathrm{n}^{\mathrm{o}} 15.783 / 22$ supramencionado foi promulgado. Já no Caso Lage, o mesmo ocorreu, mas havia lei que autorizava a arbitragem. O STF determinou que o juízo arbitral sempre foi consagrado no direito brasileiro, até mesmo em causas contra a Fazenda, e que pensar de modo contrário é restringir a autonomia contratual do Estado ${ }^{17}$. Sendo assim, para resolver a pendência do valor a ser pago em decorrência da desapropriação de bens com as Organizações Lage, constituída por empresas

\footnotetext{
${ }^{7}$ TCU, DOU 22 mai. 1995, Decisão 188/95, Plenário, Rel. Min. Paulo Affonso Martins de Oliveira. Revisor Min. Carlos Átila Álvares da Silva. Interessados: Diretor-Geral do DNER e Representante Legal do Consórcio Andrade Gutierrez/Camargo Corrêa. Entidade: Departamento Nacional de Estradas de Rodagem - DNER.

${ }^{8}$ TCU, DOU 28 ago. 1995, Decisão 394/95, Plenário, Rel. Min. Fernando Gonçalves. Entidade: Departamento Nacional de Estradas de Rodagem - DNER. Responsável: Tarcísio Delgado.

9 TCU, DOU 28 abr. 2003, Acórdão 584/03, Segunda Câmara, Rel. Min. Ubiratan Aguiar. Entidade: Comercializadora Brasileira de Energia Emergencial - CBEE. Interessados: Federação Nacional dos Engenheiros FNE, Dep. Fed. João Paulo Cunha, Dep. Fed. Fernando Ferro, Dep. Fed. Walter Pinheiro e Dep. Fed. Eustáquio Luciano Zica.

${ }^{10}$ TCU, DOU 22 mar. 2004, Decisão 215/04, Plenário, Rel. Min. Ubiratan Aguiar. Entidade: Comercializadora Brasileira de Energia Emergencial - CBEE. Responsáveis: Mário Dias Miranda, Diretor-Presidente Interino; Marco Antônio Pereira Veloso Machado, Diretor de Gestão Corporativa e Rui da Justa Feijão, Diretor de Energia.

${ }^{11}$ TCU, DOU $1^{\circ}$ jun. 2003, Acórdão 587/03, Plenário, Rel. Min. Adylson Motta. Entidade: Departamento Nacional de Infra-Estrutura de Transporte (DNIT). Interessado: Congresso Nacional.

12 TCU, DOU 13 jun. 2003, Acórdão 631/03, Plenário, Rel. Min. Marcos Vinicios Vilaça. Entidade: Companhia Brasileira de Trens Urbanos (CBTU). Responsável: Luiz Otávio Ziza Mota Valadares. Interessado: Congresso Nacional.

${ }^{13}$ TCU, DOU 2 set. 2005, Acórdão 1.271/05, Plenário, Rel. Min. Marcos Bemquerer Costa. Entidade: Departamento Nacional de Infra-Estrutura dos Transportes - DNIT. Vinculação: Ministério dos Transportes. Interessado: Congresso Nacional.

${ }_{14}$ TCU, DOU 17 mar. 2006, Acórdão 537/05, Segunda Câmara, Rel. Min. Walton Alencar Rodrigues. Entidade: Comercializadora Brasileira de Energia Emergencial - CBEE. Interessados: Federação Nacional dos Engenheiros FNE; Nordeste Generation Ltda.; Geradora Brasileira de Energia Ltda. - Gebra; Breitener Energética S.A.; Proteus Power Brasil Ltda.; Termocabo Ltda.; Termoelétrica Potiguar S.A. - TEP; Parnamirim Energia S.A.; Destilaria JB Ltda.; Ceará Geradora de Energia S.A. - CGE; Enguia Gen BA Ltda.; Enguia Gen CE Ltda.; Enguia Gen PI Ltda.; Giasa S.A.; Termoelétrica Itaenga Ltda.; Empresa de Energia Elétrica do Brasil Ltda. - Engebra; CumMin.s Brasil Ltda.; e Companhia Energética de Petrolina.

${ }^{15}$ TCU, DOU 10 jul. 2006, Acórdão 1.099/06, Plenário, Rel. Min. Augusto Nardes. Entidades: Departamento Nacional de Infra-Estrutura de Transportes - DNIT e $19^{\mathrm{a}}$ Unidade de Infra-Estrutura Terrestre. Interessado: Congresso Nacional.

${ }^{16}$ STF, DJU 4 jun. 1918, Ap. Cív. 3.021/MG, Rel. Min. Pedro Lessa.

${ }^{17}$ STF, DJU 15 fev. 1973, AI 52.181/GB, Rel. Min. Bilac Pinto.
} 
privadas que se dedicavam a navegação, estaleiros e portos, a própria União submeteu-se a arbitragem, o que foi considerado válido.

No TFR, a arbitragem não foi $\operatorname{admitida~}^{18}$. Estabeleceu-se que autarquia, sem autorização legislativa, não poderia participar de arbitragens.

Diversamente, o TJDF admitiu a arbitragem envolvendo a Administração Pública com base em uma interpretação a contrario sensu do art. 45 do Decreto-lei $\mathrm{n}^{\circ}$ 2.300/86 ${ }^{19}$. Ou seja, como o dispositivo vedava o juízo arbitral nos contratos com pessoas físicas e jurídicas domiciliadas no estrangeiro, entendeu-se que seria admitida a arbitragem nos contratos com pessoas físicas e jurídicas domiciliadas no Brasil. Além disso, a decisão também tomou como base o Caso Lage, supramencionado ${ }^{20}$.

O TJRJ, no Caso Guggenheim, não aceitou a possibilidade de arbitragem. O Tribunal considerou que a cláusula $12.2^{21}$ do acordo entre o Município do Rio de Janeiro e a Fundação Solomon R. Guggenheim contrariava o art.37, caput, da Constituição Federal, cujo texto exige que a Administração Pública se norteie pelo princípio da publicidade ${ }^{22}$.

O TJRS, no Caso AES Uruguaiana x CEEE, não admitiu a arbitragem ${ }^{23}$. Para sustentar sua decisão, a relatora do processo se baseou no art. $5^{\circ}, \mathrm{XXXV}$, da Constituição Federal, que afirma que nenhuma lei pode excluir da apreciação do Judiciário qualquer lesão ou ameaça a direito. Com isso, negou que o art. $267^{24}$, VII do CPC pudesse afastar a tutela

${ }^{18}$ TFR, DJU 26 jun. 1989, AC 137.279/DF, Rel. Min. Bueno de Souza.

${ }^{19}$ Decreto-lei no 2.300/86, art 45: "São cláusulas necessárias em todo contrato as que estabeleçam: I - o objeto e seus elementos característicos; II - o regime de execução ou a forma de fornecimento; III - o preço e as condições de pagamento, e quando for o caso os critérios de reajustamento; IV - os prazos de início, de etapas de execução, de conclusão, de entrega, de observação e de recebimento definitivo, conforme o caso; V - a indicação dos recursos para atender às despesas; VI - as garantias oferecidas para assegurar sua plena execução, quando exigidas; VII - as responsabilidades das partes, penalidades e valor da multa; VIII - os casos de rescisão; IX - o reconhecimento dos direitos da Administração, em caso de rescisão administrativa, previstos no art. 67; X - as condições de importação, a data e a taxa de câmbio para conversão, quando for o caso. Parágrafo único. Nos contratos com pessoas físicas ou jurídicas domiciliadas no estrangeiro deverá constar, necessariamente, cláusula que declare competente o foro do Distrito Federal para dirimir qualquer questão contratual, vedada a instituição de juízo arbitral”.

${ }^{20}$ TJDF, DO 18 ago. 1999, MS 1998002003066-9/DF, Rela ${ }^{a}$. Des ${ }^{\mathrm{a}}$. Nancy Andrighi. Decisão publicada e comentada por Clávio Valença Filho, Arbitragem e Contratos Administrativos, Revista de Direito Bancário, do Mercado de Capitais e da Arbitragem 8:359.

21 “(...) a arbitragem será mantida em sigilo e (...) a existência de arbitragem ou qualquer um dos seus elementos (...) não serão revelados a qualquer pessoa além dos árbitros, as partes, seus advogados e qualquer pessoa participando dos procedimentos, exceto conforme venha a ser legalmente exigido em um procedimento judicial relativo à arbitragem ou de outra forma (...)".

${ }^{22}$ TJRJ, j. 29 out. 2003, AI 2003.002.07839, Rel. Des. Ademir Pimentel.

${ }^{23}$ TJRS, j.14 nov. 2002, AI 70003866258, Rel ${ }^{\mathrm{a}}$. Des ${ }^{\mathrm{a}}$. Teresinha de Oliveira Silva.

${ }^{24} \mathrm{CPC}$, art. 267, inciso VII: "Extingue-se o processo, sem julgamento do mérito: VII- pela convenção de arbitragem". 
jurisdicional. Ademais, baseou-se na cláusula compromissória no contrato original entre as partes que determinava que as controvérsias seriam dirimidas pelas partes e, caso não houvesse consenso, poderia ser instaurado um juízo arbitral, Devido à sua redação, não foi essa cláusula tida como obrigatória. O caso chegou ao STJ, que reverteu a decisão e cujo julgado será objeto de análise adiante.

No TJPR, no caso envolvendo a COPEL x UEG Araucária, não foi a arbitragem admitida, inicialmente. Na primeira instância, uma liminar em antecipação de tutela ordenou a abstenção da prática de atos relacionados à continuidade do procedimento de arbitragem $^{25}$. Não obstante, em medida cautelar inominada, decidiu-se pela suspensão de tal ordem $^{26}$. Diferentemente ocorreu nos Casos Compagás x Carioca Passarelli ${ }^{27}$ e Energética Rio Pedrinho $\mathrm{x} \mathrm{Copel}^{28}$, nos quais se admitiu a arbitragem desde o início.

$\mathrm{Na}$ controvérsia entre a Companhia de Gás e o consórcio, vários argumentos foram dados pelo tribunal a favor da arbitragem. Primeiramente, a constitucionalidade e legalidade da arbitragem no Brasil. Além disso, o fato de economias mistas serem reguladas pelo direito privado, nada impedindo a solução de seus conflitos por via arbitral. Por fim, conclui o julgado que casos que não envolvam direitos indisponíveis ou interesse público, ou seja, que tratam apenas de questões econômicas e versam sobre direitos disponíveis, podem adotar a arbitragem ${ }^{29}$. Já no segundo processo, de forma semelhante, estabeleceu-se que a comercialização de energia elétrica é direito disponível, de acordo com o art. $4^{\circ}, \S \S 5^{\circ}$ e $7^{\circ}$ da lei $10.848 / 04$, não sendo necessária a suspensão do processo de arbitragem ${ }^{30}$.

O STJ, por sua vez, tem confirmado a tendência favor arbitratis e, em decisões recentes, admitiu que sociedade de economia mista pode se submeter à arbitragem no que toca os seus direitos disponíveis. Em um recurso especial, a $2^{\text {a }}$ Turma declarou:

\footnotetext{
${ }^{25}$ Liminar em antecipação de tutela, Juíza Josély Dittrich Ribas, em 3 jun. 03.

${ }^{26}$ TJPR, DO $1^{\circ}$ jul. 2004, MCI 160.213-7/PA, Rel. Des. Ruy Fernando de Oliveira.

${ }^{27}$ TJPR, DO 20 fev. 2004, AC 247.646-0/PA, Rel. Juiz Lauro Laertes de Oliveira.

${ }^{28}$ TJPR, DO 30 set. 2005, AI 0169656-8/PA, Rel. Juiz Fernando César Zeni.

${ }^{29}$ Cumpre apenas uma observação sobre a natureza da atividade desempenhada pela Compagás. O Tribunal curiosamente reconheceu que a Compagás, que é uma sociedade de economia mista exploradora de gás canalizado, explora atividade econômica, em aparente contradição com o art. $25, \S 2^{\circ}$, da CF/88 (com redação dada pela EC $n^{\circ}$ 5/95), que dispõe que "cabe aos Estados explorar diretamente, ou mediante concessão, os serviços locais de gás canalizado, na forma da lei, vedada a edição de medida provisória para a sua regulamentação." Ou seja, de acordo com a Constituição, a atividade de gás canalizado é uma concessão de serviço público e não uma exploração de atividade econômica.

${ }^{30}$ TJPR. DO 25 nov. 2005, AI 174.874-9/PR, Rel. Juiz Conv. Fernando César Zeni.
} 
"3- São válidos e eficazes os contratos firmados pelas sociedades de economia mista exploradoras de atividade econômica de produção ou comercialização de bens ou de prestação de serviços $\left(C F\right.$, art.173, $\left.\$ 1^{\circ}\right)$ que estipulem cláusula compromissória submetendo à arbitragem eventuais litígios decorrentes do ajuste" ${ }^{31}$.

Esse mesmo argumento foi utilizado em um caso entre a União e a TMC Terminal Modal de Coroa Grande SPE S/A, no qual o Caso Lage também foi relembrado. Além disso, enfatizou-se a distinção entre interesses públicos e interesses administrativos, afirmando que estes não são indisponíveis ${ }^{32}$.

Um dos maiores exemplos da controvérsia em questão é o supramencionado caso AES Uruguaiana Empreendimentos Ltda. x CEEE que, em recente de decisão, trouxe novamente o tema à tona. No caso, a Companhia Estadual de Energia Elétrica (CEEE), sociedade de economia mista com sede no Estado do Rio Grande do Sul, ajuizou uma ação contra a AES, na qual alegou que esta descumpriu injustificadamente contrato firmado entre elas para a aquisição de potência e energia elétrica.

A AES contestou, sustentando a existência, no contrato firmado entre as partes, de cláusula compromissória convencionando a instauração de juízo arbitral na hipótese de conflitos. Requereu, assim, a extinção do processo sem julgamento do mérito, nos termos do art. 267, VII, do Código Processual Civil.

No TJRS, a preliminar de extinção do processo sem julgamento de mérito, em razão da existência de convenção de arbitragem, foi rejeitada ${ }^{33}$, como já mencionado anteriormente. Ademais, a CEEE foi considerada prestadora de serviço público essencial, não podendo abrir mão do devido processo legal para dirimir seus conflitos.

A AES, então, interpôs agravo de instrumento previsto nos arts. 522 e seguintes do CPC. O TJRS negou provimento ao apelo à unanimidade, por concluir que é livre o acesso ao Poder Judiciário.

Em recurso especial, a AES defendeu que a cláusula compromissória é obrigatória para a solução de conflitos surgidos na execução do pactuado, de forma que o acórdão recorrido, ao negar a eficácia à referida cláusula e, por conseguinte, não extinguir o processo sem

\footnotetext{
${ }^{31}$ STJ, DJU 14 set. 2006,REsp 612.439/RS, Rel. Min. João Otávio Noronha.

${ }^{32}$ STJ, DJU 14 ago. 2006, AgRg no MS 11.308/DF, Rel. Min. Luiz Fux; DJU 30.out.2006, EDcl no AgRg no MS 11.308/DF, Rel. Min. Luiz Fux.

${ }^{33}$ TJRS, j.14 nov. 2002, DO AI 70003866258, Rel ${ }^{\mathrm{a}}$. Des ${ }^{\mathrm{a}}$. Teresinha de Oliveira Silva.
} 
julgamento de mérito, contrariou o disposto nos arts. $3^{\circ}, 4^{\circ}, 7^{\circ}, 8^{\circ}$ e 20 da Lei 9.307/96 e 267,VII, do CPC.

O STJ, por sua vez, extinguiu por unanimidade o processo instaurado pela CEEE contra a empresa AES Uruguaiana, sem julgamento de mérito. O entendimento cunhado pela corte foi o de que a vontade manifestada pelas partes de submeter a controvérsia ao juízo arbitral não pode ser afastada unilateralmente e, assim, deve ser mantida. No que tange à possibilidade de a sociedade de economia mista celebrar contrato contendo cláusula compromissória, reputou-se ser válida a cláusula e dispensável a necessidade de autorização do Poder Legislativo estadual para que se possa realizar tal procedimento ${ }^{34}$.

De acordo com o Ministro Relator João Otávio Noronha,

“[o] juízo arbitral, havendo suposto litígio, não poderá ser afastado unilateralmente, de forma que não poderá apenas uma das partes contratantes impor seu veto ao procedimento arbitral. Com efeito, ante a existência de cláusula compromissória, permite-se à parte interessada em resolver eventual litígio tomar a iniciativa para a instauração da arbitragem, ficando a outra, uma vez efetuado o pedido, obrigada a aceitá-la, de modo que não há possibilidade de a parte discordante optar entre a jurisdição estatal e o procedimento arbitral".

Ambas as empresas embargaram essa decisão ${ }^{35}$, sendo que os embargos de declaração da AES foram acolhidos e os da CEEE rejeitados. Aquela garantiu a inversão da sucumbência, ou seja, determinou-se que a CEEE arcará com os ônus, fixados em R \$ 50.000,00. Já os embargos opostos pela companhia de energia elétrica não foram acolhidos por não se enquadrarem nos termos do art 535 do $\mathrm{CPC}^{36}$, pois teriam como objetivo conferir efeito infringente ao julgado, e por requererem prequestionamento de dispositivos constitucionais, competência do STF.

Recentemente, em um diferente Recurso Especial $^{37}$ do mesmo caso objeto deste comentário - , o STJ consolidou posição de dar validade ao juízo arbitral como solucionador de conflito nos contratos de natureza econômica. Além disso, estendeu às sociedades de economia mista a possibilidade de recorrer à arbitragem nos contratos de natureza puramente comercial.

\footnotetext{
${ }^{34}$ STJ, DJU 14 set. 2006, REsp 612.345/RS, Rel. Min. João Otávio Noronha.

${ }^{35}$ STJ, unânime, DJU 6 jun. 2007, EDcl no REsp 612.439/RS, Rel. Min. João Otávio Noronha.

${ }^{36}$ Código de Processo Civil, art. 534: "Cabem embargos de declaração quando: I - houver, na sentença ou no acórdão, obscuridade ou contradição; II - for omitido ponto sobre o qual devia pronunciar-se o juiz ou tribunal”.

${ }^{37}$ STJ, DJU 8 jun. 2007, REsp 606.345/RS, Rel. Min. João Otávio Noronha.
} 
A Segunda Turma entendeu, por unanimidade, que, quando os contratos envolverem serviço de natureza industrial ou tipicamente econômica, os direitos e obrigações são transacionáveis, portanto sujeitos à arbitragem. Quando, porém, as atividades decorrerem do poder de império da administração e sua consecução estiver diretamente relacionada ao interesse público, não será possível a arbitragem ${ }^{38}$.

Todavia, constata-se ainda uma enorme insegurança a respeito, visto que a questão é polêmica e não tem recebido tratamento uniforme da jurisprudência.

Em suma, atualmente, nas hipóteses onde há lei autorizativa, não há dúvida acerca da possibilidade de a Administração clausular a arbitragem. Já nas outras situações, prevalece a incerteza, o que é bastante nefasto para um Estado que nas esferas federal, estadual e municipal, precisa do capital privado para a realização de obras das mais diversas espécies. Notese, porém, uma tendência bastante nítida por parte da jurisprudência nacional da aceitação da arbitragem envolvendo sociedade de economia mista e empresa pública que desempenham atividade econômica com base no art. 173, § da CF.

38 Vale destacar que ambos os recursos especiais do caso trataram da mesma demanda, das mesmas partes e do mesmo objeto, mas foram originados de agravos diversos na origem. O primeiro, então, também tratou da extinção de ação cautelar preparatória. 